\title{
The whole Process of Quality Supervision and Management to Scientific Research Project of Armored Equipment
}

\author{
Di Wang ${ }^{1, a}, \mathrm{He} \mathrm{Cui}^{2, \mathrm{~b}}$ \\ ${ }^{1,2}$ changchun engineering technology college, Changchun, 130117, China \\ a,bemail: 22243820@qq.com
}

Keywords: armored equipment, scientific research project, the whole process, administration of quality supervision

\begin{abstract}
Armored equipment is an important component of the army, armored equipment scientific research is the main way for equipment support. Modern war with the advanced nature of the armored equipment, reliability, security and protection are also put forward higher requirements, improve the quality of armored equipment scientific research project management level for the promotion of weapons and equipment's combat capability is of great significance. This article through to the present situation of the whole process of quality supervision and management in scientific projects of armored equipment were analyzed, and puts forward the corresponding armored equipment scientific research project of total quality management strategy, in order to improve our military armored equipment operational capability and support capability to provide theoretical support.
\end{abstract}

\section{Introduction}

Armored equipment as the implementation of the main weapons and equipment and the safeguard land operations, is an important symbol of national defense modernization and military modernization, but also an important guarantee of victory in the future regional hi-tech war. Armored equipment scientific research project is around improve equipment an important link of the combat capability and support capability, to carry our army battle effectiveness level and to protect the interests of national security is of great significance. Supervision and management is the objective requirement of the socialization production and product directly. As long as people in the society to work together and cooperate with each other, there must be supervision and management, its purpose is to make everyone for a common goal to make the best contribution. With the progress of the society, the division of refinement, the expansion of scale, complex technology, supervision and management is becoming more and more important and complicated.

Project management is accompanied by the needs of large project implementation and management, and as a discipline and a specific management method, is a kind of applicable to engineering project management mode and method system. The whole process of quality supervision and management is a form of project management, is for all the general quality of the whole process of management.

\section{The Present Situation}

Armored equipment scientific research project, is to use science and all kinds of craft and technology research and development equipment and the behavior of the general equipment support technology. In recent years, with machinery, electric power, electronics, control and the development of computer technology and the advancement of military information construction, supported by armored equipment scientific research in our country, the military information warfare capability of main equipment, has been great progress in our country. At the same time, the armored equipment support, nature and the function in the field of security technology revolutionary change, scientific research put forward higher requirement of armored equipment. However, there are problems in the concrete practice of the current and short board, in practice the scientific research project quality management still exist many deficiencies. 
First, although the armored equipment research and development and support of our country has made obvious progress, but compared with other developed countries, the whole process of quality management in scientific projects of armored equipment professional management personnel, there are great gap. Second, at present, our country in armored equipment scientific research system of lack of the whole process of quality management system and strict military standard, led to research the whole process of quality management in armored equipment is not enough scientific. Third, in the whole process of quality management in scientific projects of armored equipment, and also there is a scientific research project quality management technology lag behind, there will be not in front of the armored equipment production found the problem in advance, to correct the problem such as ease as, caused a lot of time, energy and resource waste. In addition, in the whole process of quality management in scientific projects of armored equipment, has yet to realize the comprehensive informatization and networking, modernization, make the equipment cannot be efficient for scientific research and management.

The existence of these problems, a serious impediment to the whole process of quality management in scientific projects of armored equipment to further improve the level of that increase the risk of armored equipment research, affect our army weapon equipment system construction and development. Therefore, in the concrete of the armored equipment scientific research project in the process, we must value and optimize the quality supervision and management work.

\section{Overview of Armored Equipment Scientific Research Quality Supervision Management}

Armored equipment scientific research refers to the development of new weapons and equipment, improve the existing armored equipment as the goal of scientific research activities. Armored equipment scientific research based on military requirements, weapons and equipment, technology can be converted to ultimately achieve the development and progress of armored equipment, improving the capability of the armored equipment. Armored equipment scientific research the whole process of quality management, quality, progress and cost is known as its main control coordinates. Project team as direct implementers of the project, its fundamental purpose is to provide the quality in within the time limit prescribed by the contract, the superior quality products to benefit as much as possible. This shows from three aspects that schedule, quality and cost is the most important thing in a equipment scientific research project of three parts. There is close relationship between each other, the three are mutually restricted influence each other, at the same time work content is relatively independent.

Modern project management theory is that divides into the target management quality management, schedule management and cost management, and introduced in detail, the correlation among, inseparable. Equipment scientific research project is no exception. The author thinks that the relationship of quality, progress and cost can be described in A triangle, because the basic properties of the triangle is the side of the change will affect other side, as shown in figure 1 , the edge of A inevitably lead to the change of B and C. Triangle, however, it is not enough to accurately describe the relationship among quality, progress and cost. Isolation, the quality is normal polarity index, namely the bigger the better. Progress is moderate type indicators, namely modest; Cost is negative polarity index, namely as small as possible. The three cannot simply to scale with straight line. Decision-making and evaluation issues, deal with the principle of these three types of indicators is not the same, here also can't equate.

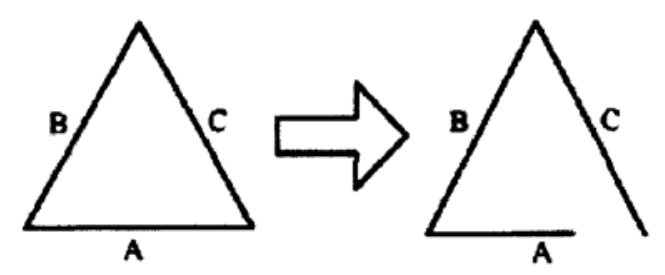

Figure 1 three coordinates the trilateral relations 
Quality management is the core of the scientific research project, the quality is the first index of scientific research project, good performance is likely to make the equipment long service life, low malfunction, easy maintenance, easy to safeguard. In peacetime, especially in the usual operations preparation process, the principle of "quality first" is the defense industry sector and the military must adhere to and constantly advanced quality management theory, method and means, to carry out a variety of effective to ensure the quality of equipment activities. Especially some key national development strategy of weapons and equipment, the main would take into account the "quality" of the equipment, to produce equipment can use, deter, basically see the performance optimization is not good, it mainly depends on the quality of the equipment. Under the principle of "quality first", the project can have a lot of cost, in the high cost, take a very long time to get these equipment, the pursuit of "good quality", is the basic goal of quality, the higher the better.

Schedule control is the foundation of scientific research project, as well as scientific research project of "leading", in the quality, progress and cost of the three, schedule management in the whole project control targets, control system and coordination, the leading position of the other. Supervision department of equipment development, production and quality control is based on mastering the whole production process, according to the schedule, the development of key nodes are key. Project progress plan not only rules the project time node, at the same time stipulated in each time node equipment should reach the state of technology, which is the basis of supervision department to control the project schedule.

Cost is higher and the unit is important issues of common concern. In recent years of equipment scientific research project, increased costs has become a universal problem. Equipment economic affordability has become equipment reliability, maintainability, supportability, besides the most important features. Therefore, must to the cost of the strict supervision and management of scientific research project, combined closely with the project schedule and quality management, and gradually improve the project cost control.

To the whole process of quality management of weapons and equipment research, is at various stages in the project how to determine the quality, how to control the progress and cost. In the process of the actual research project, affected by different environments and conditions. The mutual relations between and among quality, progress and cost is not fixed. So the supervision department in the scientific research project management is not only to complete the project schedule, quality, cost management, but also on the whole, comprehensive management of the three coordinate the relationship between each other, make whole project to achieve the optimal.

\section{Supervision and Management of the Project Examination and Approval Stage}

This stage is the key to the scientific research project management, mainly includes three aspects, namely the organization and review project proposal, project feasibility and conclude a contract for the project or the power of attorney.

General scientific research project application as follows: first, be lodged by the research unit organization review this unit's major scientific research project proposal, make a careful selection; To determine through review and feasibility of the project project establishment; The last presided over by the project units and project director to sign the contract.

Review the main principles and standards of scientific research project.Audit choice should follow when innovative scientific research project, feasibility, availability, the principle of rationality, etc. That should be mastered in the concrete of the main criteria is: whether the scientific research project is proper, the selected topic whether targeted, goals determine whether reasonable, etc.

In the scientific research project in our country at present there are still some problems in the project work. Main problems is lack of innovative scientific research project; Research foundation is weak, lack insufficient prophase research accumulation and research conditions; Team members structure is unreasonable, the quantity need to be strengthen; Now restriction of scientific research system and mechanism to promote the quality of scientific research project declaration, etc. 


\section{The Supervision and Administration of Scientific Research Project Implementation Stage}

Scientific research project implementation stage, is mainly refers to the scientific research project after the project implementation until the scientific research achievements in this stage before acceptance. This stage is the whole process of key and core of scientific research project. This stage includes control and develop the scientific research project of two aspects. Project bidding, project manager will be in accordance with the time set in the project specification, procedures and technical route to organize the implementation. This stage, the content of the scientific research project supervision and management work more various, mainly manifested in two aspects: one is in the process of the topic, provide project subject specification or in the contract to determine the various supporting conditions for the project, to rely on the project or sub-project in cost accounting, to supervise all its funding, responsible for project funds of financial management and accounting, the examination and approval of large instruments and equipment spending and the exchange cost, management expenses, accept the supervision of the superior authorities, check, etc. It is to be conducted in the supervision and inspection of control, establish the whole process, the omni-directional tracking feedback mechanism for supervision and inspection, understand the execution, feedback, to seek the solution, make sure project run smoothly as planned.

Scientific research is the main task of the project implementation stage under the condition of limited resources, in order to ensure the scientific research project to optimize the quality, cost and schedule, at the same time try to take various measures to reduce the risk of project failure. Project quality, progress and cost control is the most important elements of project management and control, as well as scientific research of the basic elements of assessment of project objectives and the key point of process control management. The following are the three aspects of content respectively in the scientific research project how to carry out supervision and management.

\section{The quality of the scientific research project supervision and management.}

Scientific research project is a programmatic creative labor, its management process is on the basis of the general project management process, combining the characteristics of scientific research project, on the basis of the management process for quality control. Main purpose is to ensure that the projects can be within a reasonable time limit for a project, the lowest possible costs to achieve the highest possible level of quality. Project quality supervision management includes two aspects of content: the first is the supervision of project quality management, the other is project to produce the quality supervision and management of content.

Project quality supervision and management of the main methods and tools are "total quality management", "quality statistics law", "quality control (QC) team", "standards of ISO9000 quality management system certification method". , no matter choose what kind of supervision and management methods should be combined with the characteristics of the scientific research project. The characteristics of scientific research projects decide the quality of the scientific research project target is difficult to fully use the method of quantitative control, can only is the combination of qualitative and quantitative methods, in the scientific research project plan of the project quality plan is often part of the quantitative, mostly in the form of normative requirements.

\section{Time supervision and management of scientific research project.}

Time supervision and management of scientific research project, it is to point to in the scope of the project is determined, to implement the goal of the project, form the project output and finish the work as described in the scope of the project plan and carry out a kind of supervision and management activities. Time supervision and management of scientific research project, including the main contents are: estimate the duration of the entire project; Develop a plan of project construction period; Sequence of project activities, project time limit for a project and the project activities needed resources is analyzed, and according to the analysis of time limit for a project progress plan.

Different time application of the content of the supervision and administration of supervision and management method is also different. Usually plan arrangement and main methods are: describing the project activity order sequence diagram method (PDM) and arrow diagram (ADM). The main 
method of project activity duration estimating the expert evaluation method, analogy method, simulation method, etc. Scientific research project is now in general to supervise the way according to the contract, mostly macroscopic supervision and management. In the process of project implementation, there will be a variety of reasons cause can't finish it on time and delay of the project, or even cancel the item, the serious influence the quality of the scientific research project plan and seriousness, it is necessary to use scientific method to develop scientific research project schedule, you can apply project actual supervision and management of critical path (CPM) and program review technique (PERT) method.

\section{Cost of scientific research project supervision and management.}

Project cost, it is to point to to achieve project objectives and carry out various kinds of project activities, and form all kinds of resources consumed cost overall. The supervision and administration of the project cost is the guarantee for actual cost is less than the project budget and project to carry out the project resource planning, project cost estimation, project budget and project supervision and management of the budget control, etc. There are many kinds of supervision and management of the modern project cost method, each method has its own advantages, disadvantages and suitable conditions are more scientific and objective reflect the law of the project cost method has three types: supervise the whole process of project cost management theory and method of project cost in whole life cycle of the theories and methods of supervision and management and the theory and methods of supervision and management of project cost.

Now our army in the supervision and management of scientific research project investment is growing, but improper use scientific research funds nervous, funding has been a research projects such as the problems existing in the supervision and management. How will get the most effective, the least amount of inputs is important issue of research the supervision and administration of the project cost. Using the technology and methods of the supervision and administration of the project cost to full budget supervision and management of scientific research project, refine the budgeting, check in time tracking costs and expenses budget biased, can relieve the strain on resources, prevent the abuse of funds, reduce unnecessary spending, in order to improve the scientific research funds utilization rate, strengthen the supervision and management of scientific research career ability.

\section{Supervision and Management of Summary Evaluation Stage}

\section{Evaluation of content.}

The summary evaluation of scientific research project, is the input and output of scientific research project of academic value, economic and military benefits comprehensive performance evaluation.

\section{Evaluation method.}

Evaluation of scientific research project, now pass two basic evaluation methods: quantitative index evaluation method and the expert qualitative judgment method. Due to the scientific research of the concept of "quality" is very complicated, only certain aspects of its visible measurement indicators. Therefore, the evaluation should be combined with two methods.

At present, used in the quantitative and qualitative approaches to the study of the evaluation can be subdivided into: peer expert evaluation method, fuzzy comprehensive evaluation method, artificial neural network, fuzzy cluster analysis, analytic hierarchy process (ahp), the literature measurement, etc. At present, the most widely used is the scientific measurement method and the peer review.

\section{Evaluation of general procedure.}

In general, can put the evaluation of the whole process is divided into three phases: evaluation of the overall design and planning stage; Evaluation of implementation stage; the evaluation results.

\section{Evaluation principle.}

In order to ensure the implementation of the evaluation objectives, evaluation must follow the following principles: scientific research project independence principle, systematic principle, principle of effectiveness, reliability principle, the frugal principle and so on. 


\section{Conclusion}

In this paper, according to the characteristics of the equipment scientific research project, this article from the project quality management, schedule management, project cost control with three factors, at the different stages of the scientific research project how to carry out supervision and management are analyzed in detail. Equipment of scientific research is a highly complex and has a great risk of work, how to improve the efficiency of scientific research, also is the scientific research project supervision and management and the focus of scientific research personnel, inspection theory, through practice to find and fix problems and continue to promote the development of the theory, also is one of the direction to further research in this paper.

\section{References}

[1]General Services Administration, Department of Defense, National Aeronautics and Space Administration. Federal Purchase Regulation[S].March 2005.

[2]Carol Rockey. Ministry of Defence Policy Paper No.4 Defence Purchase [M].London Britain.Director General Corporate Communication.200 1.12.

[3]Department of Defense U.S.FA8770-04-Q-0029.Evaluation Factors for Award of DEAMS[S], Attachment 3 of Air Force Materiel Command Federal Purchase Regulation Supplement Solicitation Provisions.2004.

[4]Sandia National Laboratories. Purchase Planning Guidelines--1.1.G[S], 2004.7.

[5]Chong Meng,Huawen Song.Total quality management target analysis method study[J].Industrial Engineering and Management,2012,01(34):152-153. 